\title{
BIM IMPLEMENTATION FOR STRUCTURAL DESIGN COURSES IN CIVIL ENGINEERING
}

\author{
JUAN C. POMARES, F. JAVIER BAEZA, FRANCISCO B. VARONA \& DAVID BRU \\ Department of Civil Engineering, University of Alicante, Spain
}

\begin{abstract}
Building information modelling (BIM) is a collaborative work methodology for the creation and management of a construction project. Its aim is to centralize all project information in a digital information model created by all agents involved in its development. BIM supposes the evolution of traditional design systems based on plans, since it incorporates geometric (3D), time (4D), costs (5D), environmental (6D) and maintenance (7D) information. Furthermore, BIM is not limited to the initial design phases, as it also covers the execution of the project and even the life cycle of the building. During the last decade, BIM methodology has been progressively implemented in different countries, becoming a priority for their Public Administrations. Following the recommendation of the European Directive of Public Procurement 2014/24/EU, BIM is progressively being requested in public works, e.g. The Spanish Ministry of Public works created in 2015 the National Committee of BIM, in which BIM implementation in the architecture, engineering and construction (AEC) industry and how to introduce it in public tenders are being considered. This progressive implementation of BIM by public administrations is transforming AEC industry. Therefore, universities should include BIM formation in AEC related studies, in order to prepare future engineers for this new scenario. In this work, a critical review of different approaches for BIM implementation in structural design of Civil Engineering Degree is made.

Keywords: BIM, digital model, civil engineering, structural analysis, higher education.
\end{abstract}

\section{INTRODUCTION}

Building Information Modelling (BIM) appeared as a paradigm shift for the architecture, engineering and construction (AEC) industry. BIM is based in collaborative work for the whole construction project, either during its design, construction, management or even maintenance phases. Its main objective focuses on the centralization of all project-related information in a single digital model comprising all different activities of each agent involved in its development. Therefore, BIM changes the traditional plan-based design (including independent drawings for each activity), and proposes an interactive and interrelated design considering additional information, i.e. new dimensions such as: tridimensional geometrical data (3D); timeline for work schedule (4D); costs and economic data (5D); environment and location (6D); or life-time maintenance program (7D). This multidimensional model is design to surpass the initial design phase, and also include all life-cycle of the structure, i.e. construction, maintenance and demolition/recycling. Hence investment decisions could be based on much more complete data, which comprise all functionalities and cost-related issues, or even sustainability perspective, related to the final service life prevision, recycling possibilities or energy efficiency. Conflict detection and solving is one last BIM advantage, i.e. interferences between different partners involved in the project can be easily detected in the initial design. Thus project construction will have to face less unexpected decisions, and the overall project management will benefit from quick conflict solving tools. As a summary, BIM collaborative based methodology will increase design efficiency, and consequently project quality.

During the last decade, BIM methodology has been progressively gaining weight in AEC industry. And it is becoming a priority for different Public Administrations at all levels, i.e. 
local, national and international. For example, European Directive 2014/24/UE recommends BIM implementation as a basic requirement for all public funded works and infrastructures. In particular, Spanish Administration - Ministerio de Fomento - following the aforementioned Directive, created in 2015 a Committee for BIM implementation in Spain [1]. The main objectives of this work group comprise BIM promotion in construction sector; BIM use encouragement through complete life-cycle of infrastructures; Public Administrations awareness of the necessity of BIM requirements in public contracts; national standards development, and a scheduled program for current standards adaptation, for a regulated and generalized use of BIM; even an academic map for BIM formation in Spanish education at different levels. The effects of BIM introduction in Public Administrations is actually changing AEC industry. Therefore, Universities and Higher Education Schools shouldn't ignore this new scenario, and BIM education inside AEC-related degrees and specialization courses should be discussed and put into practice.

Related to this new scenario frame, the present paper includes a brief state of the art regarding BIM use experiences in Higher Education, especially in the field of structural design and analysis of Civil Engineering and Architecture structures.

\section{PROJECT DESIGN, CONSTRUCTION AND MANAGEMENT WITH BIM TOOLS}

First, a brief summary of BIM effect in the different parts of a construction project has been included. In Spain, everyday new contractors, and architecture or engineering studios adapt their working procedures including BIM tools, which help them managing information since project design to its construction and life-service control. Therefore, the role of Public Administrations, is crucial to define the standards for documents and procedures. For example, COBie (Construction Operations Building information exchange) is an international standardfor information transfer to optimize data interchange in management of facilities. Its use complements BIM tools and their standard IFC format, which enables BIM data communication between project partners, even if they use different software families. Then the main advantages of BIM can be organized depending on the project stage they belong to:

- Predesign and investment decision: the multidimensional characteristic of BIM enables the comparison of multiple factors between potential solutions during the decision making process. Therefore, more precise cost assessments can be done with different alternatives [2].

- Project development: the construction is designed directly in 3D environment, and every part can be included (foundations, structure, piping...), hence conflicts between different facilities can be easily predicted and solved by project's engineers and architects. Therefore, the design will be more accurate, and all graphical documents required can be prepared, since general architectonic views to specific constructive details, Fig. 1(a). Moreover, staff meetings will have enhanced documents directly from the BIM model, especially compared to traditional plans and diagrams.

- Construction: first the enhance coordination between engineers and architects during the design phase undoubtedly reduces the amount of conflicts in construction. Besides, BIM models developed during project design can be useful for contractors, as a base for work planning that will update the original BIM model as each work advances. Clients can also supervise on real-time the status and modifications made on the initial project [3]. Coordination between agents can be improved due to 3D simulations of the constructive process, which will lead to preventive conflict solving. Consequently, construction safety is definitely better, and BIM becomes also a tool 
useful for the safety plan development, helping in the decision for the optimal protective measure in every case, either collective or individual.

- Maintenance and service-life management: the maintenance works planned during project design can be followed with the same BIM model, Fig. 1(b). Besides sustainability can be enhanced with a proper energy and waste management. BIM can help with energy efficiency studies and monitoring, for quality assessment of the constructed solution [4]. And finally, demolition and recycling can also be planned since project beginning. The following figures have been created with the help of Revit software.

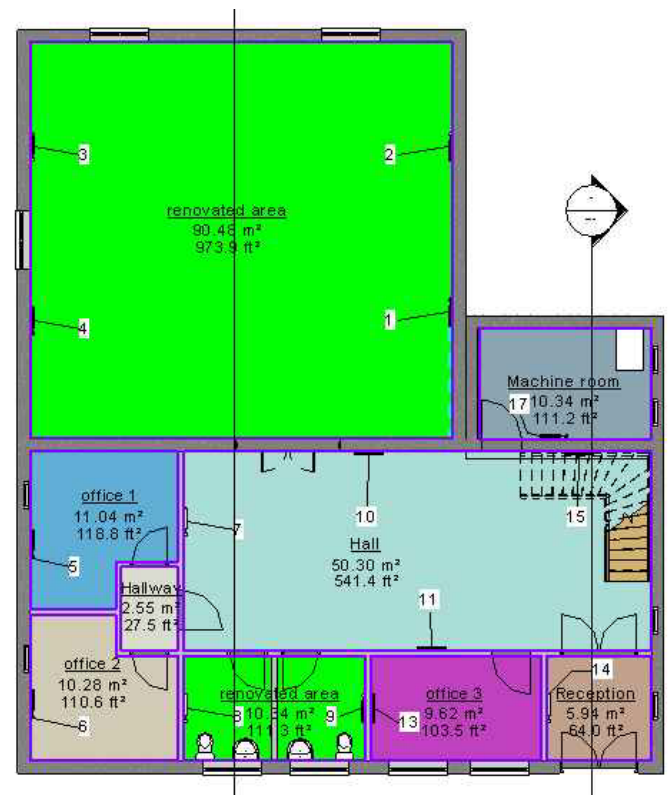

(a)

\begin{tabular}{|c|c|c|c|c|c|c|}
\hline \multicolumn{7}{|c|}{ maintenance planning } \\
\hline Level & Name & \begin{tabular}{|l|} 
Area $(\mathrm{m} 2)$ \\
\end{tabular} & Perimeter (m) & Price (f) & Cost & Comments \\
\hline Level 0 & renovated area & 90.48 & 38.07 & 600 & $54,288.00$ & to paint every 2 years \\
\hline Level 0 & office 1 & 11.04 & 14.23 & & & to paint every 4 years \\
\hline Level 0 & office 2 & 10.28 & 13.65 & & & to paint every 4 years \\
\hline Level 0 & Hallway & 2.55 & 6.51 & & & to paint every 2 years \\
\hline Level 0 & Machine room & 17.34 & 13.17 & & & to paint everty 10 years \\
\hline Level 0 & office 3 & 9.62 & 12.76 & & & to paint every 4 years \\
\hline Level 0 & Reception & 5.94 & 9.75 & & & to paint every 4 years \\
\hline Level 0 & Hall & 50.3 & 30.98 & & & to paint every 2 years \\
\hline Level 0 & renovated area & 18.34 & 13.35 & 600 & $11,004.00$ & to paint every 4 years \\
\hline Level 1 & office 4 & 12.64 & 14.23 & & & to paint every 4 years \\
\hline Level 1 & office 5 & 11.65 & 13.65 & & & to paint every 4 years \\
\hline Level 1 & Hall & 68.76 & 36.11 & & & to paint every 2 years \\
\hline Level 1 & renovated area & 8.6 & 12.75 & 600 & $5,160.00$ & to paint every 4 years \\
\hline
\end{tabular}

(b)

Figure 1: (a) General plan of BIM model; (b) Maintenance plan created with the help of Revit software. 


\section{BIM EXPERIENCES IN ENGINEERING SCHOOLS AND UNIVERSITIES}

Inside Engineering and Technical Schools, professors and lecturers should explain the importance of the theoretical concepts, and their practical applications, for the alumni future professional practice. A fluent student-professor feedback is basic to maintain the appropriate motivation during courses [5]. Today interactive learning environments represent a fundamental tool in higher education, especially in structural engineering courses, in which structural design collides with structural analysis of different typologies and infrastructures, e.g. buildings, bridges, dams, tunnels, etc. In this regard, BIM appears as an attractive environment for several courses in Architecture and Engineering degrees. It can be applied to real examples that complement and improve technical formation of Architecture and Engineering students. Every time that a new learning scenario is created some concerns about the proper way to use it appear, like the EHEA changes in syllabuses of European Universities [6]. Hence a brief revision of some experiences of BIM use in engineering courses has been made, and some possible approaches discussed.

\subsection{BIM implementation experiences}

Table 1 includes some cases reported in scientific literature regarding BIM implementation in engineering degrees. As a general approach, there are some examples that propose some guidelines for a progressive implementation of BIM [7], [8]. First, BIM formation of the University's teaching staff should be promoted. This objective can be achieved in collaboration with professional engineers and companies with a wide experience and knowledge in BIM. After, some research resources should be focused in BIM development, e.g. in collaboration with students during their dissertations. And finally, full post degree studies should be designed. These masters will serve as specialization for students, e.g. computer-aided structural design using BIM tools that will be useful for the professional activity of engineering and architecture graduates.

Table 1: Different approaches in BIM implementation in engineering degrees.

\begin{tabular}{|l|l|l|l|l|}
\hline Year & Country & Subject & Approach/ activity & Ref. \\
\hline 2010 & Brazil & $\begin{array}{l}\text { Engineering, } \\
\text { Architecture, and } \\
\text { Construction } \\
\text { Management }\end{array}$ & $\begin{array}{l}\text { Protocol for BIM use in University. } \\
\text { Advises for a successful } \\
\text { implementation. }\end{array}$ & {$[8]$} \\
\hline 2012 & Saudi Arabia & Structural design & $\begin{array}{l}\text { Structural modelling with real cases } \\
\text { application for a more efficient } \\
\text { teaching due to student's interest } \\
\text { increase. }\end{array}$ & {$[9]$} \\
\hline 2013 & Spain & Structural design & $\begin{array}{l}\text { BIM tools were used in workshops } \\
\text { for structural design and analysis: } \\
\text { visualize joint design, complex } \\
\text { geometries... }\end{array}$ & {$[10]$} \\
\hline 2016 & Brazil & $\begin{array}{l}\text { Production systems } \\
\text { engineering }\end{array}$ & $\begin{array}{l}\text { Describes different stages for } \\
\text { implementation of BIM } \\
\text { methodology in Engineering } \\
\text { Schools. }\end{array}$ & {$[7]$} \\
\hline
\end{tabular}


In Muller et al. [7], the authors present four different milestones for a successful BIM competence acquirement: (i) differentiate between BIM and traditional CAD tools, i.e. presenting all management possibilities of BIM; (ii) development of projects using BIM software, i.e. build technical and functional BIM capabilities; (iii) create detail information and documents for a fully-defined project, i.e. acquire professional BIM proficiency; and (iv) collaborative work to improve information share and coordination between agents, and generate the corresponding IFC files, i.e. improve all aforementioned capabilities.

On the other hand, an approach to BIM as a complementary tool in specific courses results easy to implant [8]. The design and real implementation of a new study plan, either under- or post-graduate, is an arduous task, which involves a lot of different areas and departments. The procedure comprises a huge amount of administrative paperwork to pass all technic and administrative controls and protocols. However, BIM can be easily adopted as a complement to some activities of a particular area, e.g. structural design or project management. In a fouryear degree, the courses during first and second year could be used to achieve a basic formation in BIM, which comprises model design and analysis tools from an individual point of view. The next year will be focused on collaborative project-based learning, in which all the issues related to simultaneous data working should be solved. And finally, students could make internships in companies developing real cases during their last year [8].

Other references present a different point of view, and are focused on specific experiences in structural engineering courses [9], [10]. In general, the learning process requires students' interest in the subject, which is directly related to solving real cases, managing multimedia tools, and including technological advances in lectures. Structural design students in particular, ask for a professional approach, to see the repercussion of the course in their future career. Therefore, course's contents and methodologies should be constantly revised and updated to keep the proper motivation. In this regard, BIM, group activities and laboratory sessions are undoubtedly useful for this purpose [9].

Another successful experience of BIM for structural analysis was held in European University of Madrid [10], in which BIM was used in their Architecture degree. The purpose of using BIM was the analyses of possible conflicts between the structural elements and other items of the project (walls, pipes, etc.). BIM models were developed in workshops with teams composed by students from different courses. The main activity was the design of reinforced concrete precast walls and prestressed concrete beams, in which rebar configuration and design was studied in a 3D geometrical model. BIM could easily define complex geometries, and was used in other examples like a parking or an office building. Moreover, the possibility of a $3 \mathrm{D}$ visualization was useful in the design of a beam-column joint of a steel structure. Finally, a complete reinforced concrete structure was analysed, including all frame elements (beams and columns) and foundation (footings).

As a summary, Universities shouldn't ignore these new methodologies related to BIM, which have already get into the market of EAC industry. These tools besides their potential for professional activities, have been proofed as an auxiliary method for construction and structural design teaching. In particular, the implementation of BIM in Civil Engineering courses allows multidisciplinary and collaborative working. In mixed workshops, the interactions between different aspects of a project (structures, costs, sustainability, etc.) can be analysed all at the same time with only one BIM model.

\subsection{Practical example}

In this last section, some examples of BIM application are included. They represent some examples of communication between different specialized software using BIM. The building 
shown in Fig. 2(a) has been designed using different software. First, the BIM model of Fig. 2(a) was modelled in a BIM environment using Revit. Fig. 2(b) includes a section of the structural model of the building, and afterwards the IFC file was exported for a full structural analysis in CYPE (Fig. 2(c)).

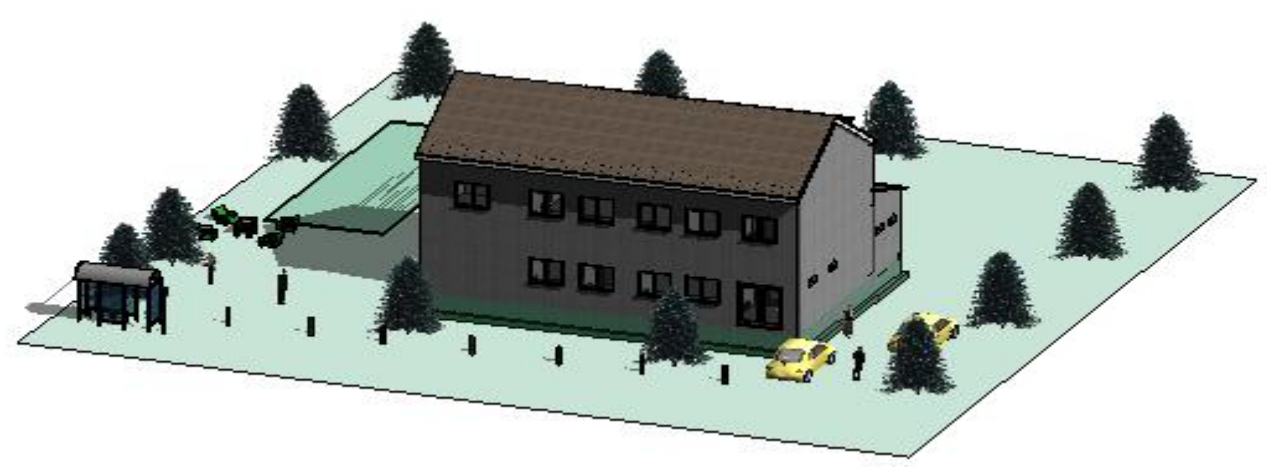

(a)

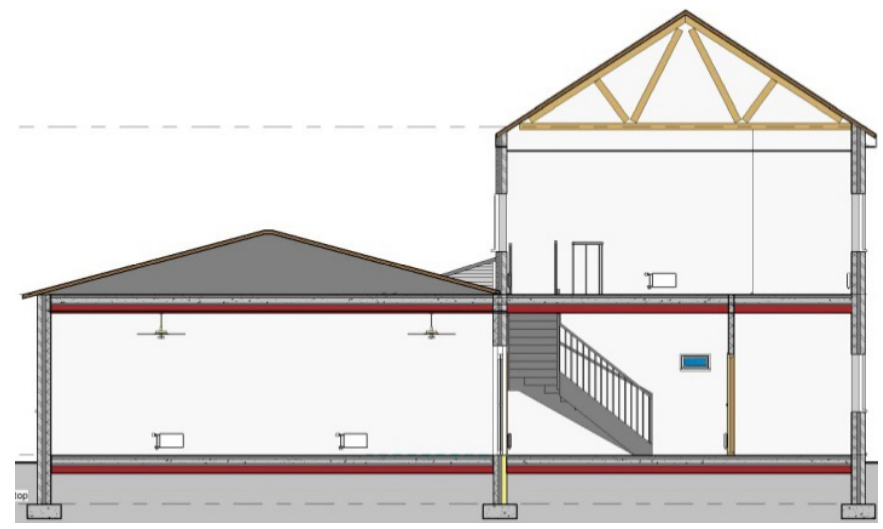

(b)

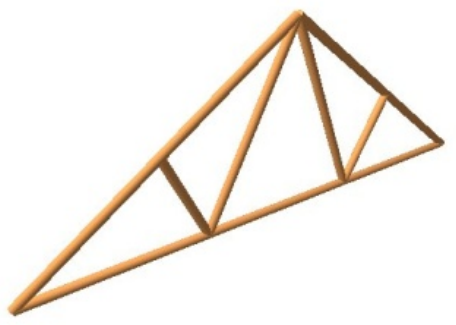

(c)

Figure 2: Building 3D model of a project designed with BIM software. (a) General view in Revit; (b) Section view of the structural model in Revit; (c) Structural model of the truss in CYPE. 
Fig. 3(a) shows a structure, located at the campus of the University of Alicante, and that could be a possible exercise to introduce BIM to the future engineering and architecture students. This structure, a former hangar for the military airport that was located in the actual campus, is very close to the buildings, where laboratories are located and lectures are held. Therefore it will be a real case study, close to the classrooms, so they could collect all necessary data in-situ. There are some special characteristics that made this case interesting as an introduction to BIM. First, some of the steel elements present signs of corrosion, Fig. 3(b), because there aren't any protective measures to prevent corrosion, and its current location inside a garden area with a little pond. Therefore, the structural health can be studied, and afterwards, the corresponding retrofitting project can be developed. Second, it's being used as a singular structure within a botanic garden, but it will be interesting to evaluate different reutilization alternatives. And consequently, a third possible study can be the structural capacity assessment in order to apply all the aforementioned interventions. Actually, some details of the structure-foundation connection are studied in a SAP2000 workshop (Fig. 3(c)).

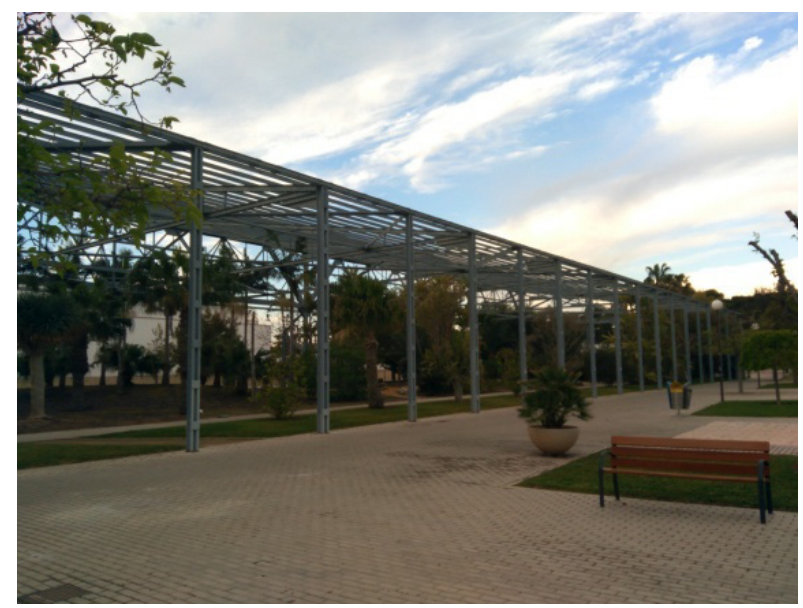

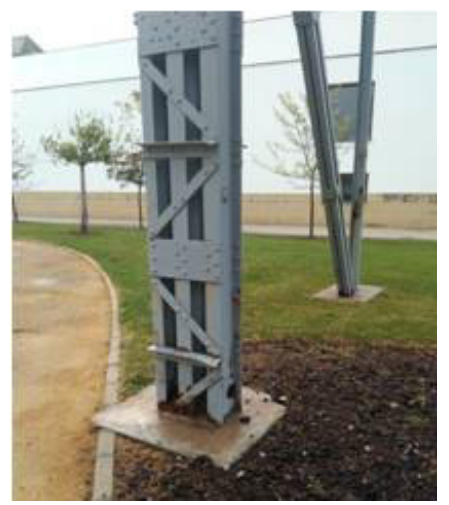

(b)

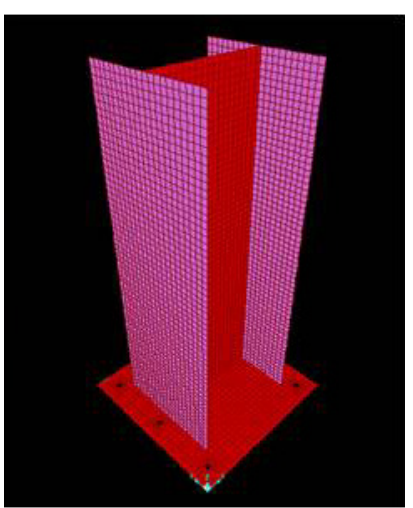

(c)

Figure 3: Steel structure at University of Alicante. (a) General view; (b) Detail of a column and foundation and corroded elements; (c) Structural model in SAP2000. 


\section{CONCLUSIONS}

The main advantage of BIM is the centralization of all project information in only one digital model, which can be generated simultaneously by all partners involved in its development. The construction industry is currently using BIM in their projects, and Public Administrations are asking their contractors for BIM models. Therefore Universities shouldn't ignore this new approach to project development. BIM formation should be included in degrees related to architecture, engineering and construction, in order to prepare the students (architects, engineers and quantity surveyors) for their future professional scenario.

BIM can be a useful tool in structural analysis and design as a more complete vision can be given, i.e. 3D modelling for a more accurate design (even for complex elements like joints) and conflict detection between structure and other constructive elements.

\section{ACKNOWLEDGEMENT}

Dr JC Pomares wants to thank the Department of Architecture and the Built Environment, at UWE of Bristol (UK), for their kindness and collaboration during his research stay at their facilities.

\section{REFERENCES}

[1] Building Smart Spanish Chapter. Documento 11 Gestión de un proyecto BIM. Oct. 2014.

[2] Building Smart Spanish Chapter. Documento 13 Uso de modelos en la fase de Construcción. Oct. 2014.

[3] Building Smart Spanish Chapter. Documento 12 BIM para Mantenimiento Operaciones. Oct. 2014

[4] Building Smart Spanish Chapter. Documento 5 Diseño Estructural. Oct. 2014.

[5] Pomares, J.C., Irles, R., Ferrer, B., González, A. \& García, J., Aprendizaje y Motivación en la Enseñanza de las Estructuras. III Jornadas Internacionales de Enseñanza de la Ingeniería Estructural, ACHE, Valencia, Jun. 2013.

[6] Baeza, F.J., Ivorra, S., Bru, D. \& Segovia, E., New technologies implementation in structures'teaching of civil engineering degrees inside the European Higher Education Area. Proceedings of International Conference on Education and New Learning Technologies - EDULEARN12, Barcelona, pp. 2985-2992, 2012.

[7] Muller, M., Loures, E., Mendes Jr, R., Canciglieri Jr, O., Do Carmo Duarte, M. \& Frederico, G.F., Developing BIM Culture in a university, past and future steps. Transdisciplinary Engineering: Crossing Boundaries, 2016. DOI: 10.3233/978-161499-703-0-358.

[8] Benardete, M. \& Toledo, E., BIM teaching strategies: An overview of the current approaches. Proceedings of the International Conference on Computing in Civil and Building Engineering, Nottingham, 2010.

[9] Ucol-Ganiron Jr, T., Student competences in structural engineering: Modelling cultural environment in Qassim University. SEFI 40 ${ }^{\text {th }}$ Annual Conference, Thessaloniki, Greece, Sep. 2012.

[10] Liébana, O \& Gómez, M., S-BIM en la docencia de estructuras para edificación. III Jornadas Internacionales de Enseñanza de la Ingeniería Estructural, ACHE, Valencia, Jun. 2013. 